\title{
Editorial
}

Maria Lucia Panossian mlpanossian@utfpr.edu.br Universidade Tecnológica Federal do Paraná (UTFPR) Curitiba, Paraná, Brasil

Veridiana Rezende rezendeveridiana@gmail.com 0000-0002-4158-2196 do Paraná UNESPAR - Campo Mourão, Paraná, Brasil

\section{Artigos, entrevistas e dossiê temático na ACTIO}

Este número da Revista Actio: Docência em Ciências é caracterizado pelo equilíbrio na relação quantidade/qualidade, com a publicação de 24 artigos distribuídos em quatro seções.

A seção "Articulações em Ensino de Ciências", apresenta um total de oito artigos. Os trabalhos variam entre investigações com alunos da escola básica e outros, que exploram a formação de professores dentro dos espaços da sala de aula, centros de ciências ou cursos de extensão, além de estudos sobre a própria produção acadêmica.

O primeiro deles, de autoria de Tatiele Chicóra, Joanez Aparecida Aires e Sérgio Camargo, investiga a epistemologia de Ludwik Fleck como referencial teórico em produções apresentadas no Encontro Nacional de Pesquisa em Educação em Ciências. Também voltado às produções do meio acadêmico, o artigo de Marcelo Souza Motta, Marco Aurélio Kalinke e Luciane Ferreira Mocrosky mapeia dissertações que articulam o uso de tecnologias educacionais e ensino de física.

A visão de estudantes sobre a participação da mulher na ciência é tema da investigação de Mariana Bolake Cavalli e Fernanda Aparecida Meglhioratti. Enquanto Tainá Cordova Schlosser e Patrícia Barbosa Pereira discutem as representações midiáticas de corpo, gênero e sexualidade na série Orange is the New Black

O artigo dos autores Nilgleice Leal Amador, Rosilene de Jesus Trindade, Paulo Weslem Portal Gomes, Eduardo Zaragoza Ramos, Ronilson Freitas de Souza investiga a modelagem matemática como estratégia didática para o ensino e aprendizagem dos temas terra e universo. Mainã Mantovanelli, Sarah de Jesus Cantarino e Geide Rosa Coelho, investigam as potencialidades e desafios para o desenvolvimento de práticas educativas em um centro de ciências. A importância da produção escrita no gênero textual artigo de opinião nas aulas de ciências é discutida no artigo de Tiago do Amaral Moraes e Marcelo Tadeu Motokane. O processo de contextualização na formação de professores de química é revelado por Moisés da Silva Lara e Luciana Gili Vieira Duarte.

A segunda seção deste número da Revista Actio trata de Produtos Educacionais em Ensino de Ciências e Matemática e é composta por três artigos. O primeiro deles é de autoria de Lilianne de Sousa Silva, Luciana Medeiros Bertini e Leonardo Alcantara Alves e analisa objetos de aprendizagem relacionados ao processo de ensino de estequiometria. A metodologia ativa baseada em projetos é usada para a proposição de uma sequência didática para o ensino de função afim, por Sebastião Luís de 
Oliveira e Estaner Claro Romão. Como modo de problematizar o ensino de modelos atômicos, o jogo como recurso didático é estudado por Luana Carol de Camargo, Sara de Simas Asquel e Brenno Ralf Maciel Oliveira.

A seção seguinte é especial. Organizada na forma de dossiê temático, contou com a colaboração de Veridiana Rezende na edição, e intitula-se Resultados de pesquisas paranaenses: um olhar sobre os aspectos teóricometodológicos presentes nas aulas de matemática.

As ideias para a organização deste dossiê nasceram de um diálogo entre docentes do Programa de Pós-Graduação em Formação Científica Educacional e Tecnológica (PPGFCET) da Universidade Tecnológica Federal do Paraná (UTFPR - Curitiba) e a coordenadora da Comissão Científica do XIV EPREM - Encontro Paranaense de Educação Matemática, realizado em setembro de 2017, na Universidade do Oeste do Paraná - UNIOESTE, Cascavel.

O Encontro Paranaense de Educação Matemática - EPREM é o maior e mais importante evento de profissionais envolvidos com a Educação Matemática no Paraná. Possibilita diálogos, reflexões e troca de experiências entre professores da Educação Básica, professores e estudantes das Licenciaturas em Matemática e em Pedagogia, estudantes da PósGraduação, pesquisadores e demais interessados pela área de Educação Matemática.

O evento é promovido pela Sociedade Brasileira de Educação Matemática - Regional Paraná (SBEM-PR). Com a intenção de reunir em um único dossiê pesquisas paranaenses sobre teoria e metodologia do ensinoaprendizagem de Matemática, foram selecionados trabalhos apresentados no XIV EPREM, respeitando os três (03) critérios elencados a seguir: i) resultados de pesquisas concluídas e apresentadas no EPREM na modalidade Comunicação Científica; ii) pesquisas que se referem a aspectos teóricosmetodológicos presentes nas aulas de Matemática; iii) autores vinculados a universidades do Estado do Paraná. Com os textos selecionados, a partir dos critérios mencionados, os autores foram convidados a ampliar seus manuscritos, modificá-los e adaptá-los às normas da revista. Nestas condições, os artigos reformulados foram avaliados por pareceristas ad hoc, resultando em 11 (onze) publicações que compõem este dossiê temático.

Os textos publicados no Dossiê refletem a diversidade de aspectos teóricos-metodológicos passíveis de desenvolvimento nas aulas de Matemática. Segue uma breve apresentação dos temas discorridos no Dossiê Temático. 0 tema Modelagem Matemática na Educação Básica é abordado pelos autores Derli Kaczmarek e Dionísio Burak, ao analisarem as interações realizadas entre aluno-aluno e aluno-professora no decorrer do desenvolvimento de uma atividade de Modelagem, em uma realização que conta como primeira experiência da professora com uma atividade dessa natureza. Já as autoras Céres de Oliveira Jendreieck e Ettiène Guérios apresentam as contribuições que um jogo educativo interdisciplinar proporcionou para o desenvolvimento de habilidades das disciplinas de matemática e geografia de alunos do 3 o ano do Ensino Fundamental. Os autores Patrick Bellei e Tiago Emanuel Klüber discutem a Modelagem 
Matemática para a Educação Matemática e suas relações com a comunidade escolar a partir da interrogação: que influências a comunidade escolar apresenta ao desenvolvimento de atividades de Modelagem Matemática para a Educação Matemática? As autoras Eliane Siviero da Silva e Lucieli M. Trivizoli apresentam uma proposta de ensino para os anos iniciais do Ensino Fundamental, por meio de uma atividade sobre sistemas de numeração baseada em informações históricas. Paulo Henrique Rodrigues, Eliane Maria de Oliveira Araman e Tiago Henrique Reis explanam o tema Tecnologias Digitais da Informação e Comunicação e História da Matemática por meio de uma abordagem relacionada ao Crivo de Eratóstenes. Já o tema Exploraçãoinvestigação matemática na Educação Infantil é discorrido pelas autoras Luciana de Souza, Maiara Aline Junkerfeurbom e Tânia Stella Bassoi. Os diferentes encaminhamentos para um mesmo tema em atividades de Modelagem Matemática são explorados pelas autoras Elida Maiara Velozo de Castro e Michele Regiane Dias Veronez. Os autores Milene Aparecida Malaquias Cardoso, Fernando Francisco Pereira e Jader Otavio Dalto tratam do tema Análise da Produção Escrita como estratégia de ensino a partir de uma experiência com o sétimo ano. Já as autoras Cileide Teixeira da Silva Polli e Helenara Regina Sampaio Figueiredo apresentam uma sequência didática para o ensino de polígonos por meio do uso de materiais manipuláveis, no quinto ano do Ensino Fundamental. As relações entre a cultura escolar do campo e o ensino da matemática são exploradas no manuscrito de autoria de Maykon Jhonatan Schrenk e Barbara Winiarski Diesel Novaes. Os autores Cleiton Antonio Marino e Marcele Tavares Mendes abordam o tema delineamento de tarefas matemáticas à luz da Pesquisa de Desenvolvimento (Design Research) e, para isso, analisam o processo de elaboração de uma trajetória de ensino e de aprendizagem - envolvida no contexto de plantas baixas - para alunos do sexto ano do Ensino Fundamental.

De autoria de pesquisadores do Estado do Paraná, os textos deste Dossiê representam a diversidade de instituições de Ensino Superior e da Educação Básica e de Programas de Pós-Graduação Stricto Sensu envolvidos com a pesquisa em Educação Matemática neste Estado.

A última seção "Entrevistas da Actio" é inaugurada neste número. As entrevistas foram concedidas por Marcelo Brito Carneiro Leão, professor da Universidade Federal Rural de Pernambuco, pós-doutor no uso da Tecnologias da Informação e Comunicação no Ensino de Ciência e Maria Aparecida Viggiani Bicudo, professora da Universidade Estadual Paulista (UNESP - Rio Claro), referência nos estudos sobre Filosofia da Educação e Fenomenologia. Os entrevistadores constituem-se de docentes e discentes do Programa de Pós-Graduação em Formação Científica Educacional e Tecnológica (PPGFCET), que atuaram durante o evento Jornadas de Educação em Ciências e Matemática, realizado em outubro de 2017, na Universidade Tecnológica Federal do Paraná (UTFPR).

Ficam os agradecimentos a todos aqueles que contribuíram direta ou indiretamente para a publicação desse número da revista, e de modo especial aos autores que realizaram as adaptações necessárias e encaminharam seus textos ao periódico; aos pareceristas que colaboraram 
preciosamente com as avaliações dos manuscritos e à equipe técnica que prontamente colaborou para a publicação deste número.

Desejamos a todos uma ótima leitura.

Maria Lúcia Panossian

(Editora da seção Educação Matemática)

Veridiana Rezende

(Editora convidada da seção Dossiê Temático) 
Recebido: 25 nov. 2018

Aprovado: 25 nov. 2018

DOI: $10.3895 /$ actio.v3n3.9109

Como citar:

PANOSSIAN, M. L.; REZENDE, V. Artigos, entrevistas e dossiê temático na ACTIO. ACTIO, Curitiba, v. 3, n. 3, p. 1-5, set./dez. 2018. Disponível em: <https://periodicos.utfpr.edu.br/actio>. Acesso em: XXX

Correspondência:

Maria Lucia Panossian

Rua Eugênio José de Souza, 993, ap. 401 - Água Verde, Curitiba, Paraná, Brasil.

Direito autoral: Este artigo está licenciado sob os termos da Licença Creative Commons-Atribuição 4.0

Internacional.

(c) (1) 